\title{
Internet applications, sites, trends and happenings
}

\author{
David Raitt \\ david.raitt@esa.int
}

This column aims to draw your attention to various interesting Web sites which I have come across and which might appeal to you, and to keep you up to date with news and views on Internet trends, developments and statistics. It offers essentially a personal selection rather than comprehensive coverage. Although some sites may not cover products or services available in South Africa, they are included because they may inspire you to either contribute missing data or become an entrepreneur and create a similar local site.

\section{Carbon cost of Google}

Apparently for every two searches you do on Google you produce as much carbon dioxide as you do when boiling a kettle, according to Harvard University academic Alex WissnerGross. He argues that these carbon emissions stem from the electricity used by desktop computers and the power consumed by the large data centres operated by Google around the world. The professor's figures of $7 \mathrm{gr} \mathrm{CO}_{2}$ per search (boiling the kettle produces $14 \mathrm{gr} \mathrm{CO}_{2}$ ) are disputed by Google, that says a typical search produces only $0,2 \mathrm{~g}$ of carbon dioxide. A recent study by Gartner suggests that IT now causes $2 \%$ of global emissions. In 2007, Google co-founded the Climate Savers Computing Initiative - a non-profit consortium committed to cutting the energy consumed by computers in half by 2010 and so reducing global $\mathrm{CO}_{2}$ emissions by 54 million tons per year. For more on Google's carbon footprints, either Google Google (cost $7 \mathrm{gr} \mathrm{CO}_{2}$ ) or go straight to http://news.bbc.co.uk/1/hi/technology/7823387.stm.

\section{Adults and social network Web sites}

The share of adult Internet users who have a profile on an online social network site has more than quadrupled in the past four years according to the Pew Internet \& American Life Project. While media coverage and policy attention focus heavily on how children and young adults use social network sites (indeed, some $65 \%$ of online teens use online social networks), adults still make up the bulk of the users of these Web sites in the USA since they represent a larger portion of the population than teens. Younger online adults, however, are much more likely than their older counterparts to use social networks, with $75 \%$ of adults aged 18 to 24 using these networks, compared to just $7 \%$ of adults aged 65 and older. Use of online social networks seems very much still a phenomenon of the young. Overall, personal use of online social networks seems to be more prevalent than professional use of networks with most adults, like teens, using such networks to connect with people they already know. To read more, including how privacy conscious adult social network users are, get the pdf from http://www.pewinternet.org/PPF/r/272/report_display.asp.

\section{Internet in 2020}

A survey of experts, including Internet leaders, activists and analysts, by the Pew Internet \& American Life Project that asked respondents to assess predictions about technology and its 
roles in the year 2020 shows they expect major technology advances as the phone becomes a primary device for online access, voice-recognition improves, artificial and virtual reality become more embedded in everyday life and the architecture of the Internet itself improves. Key findings are:

- The mobile device will be the primary connection tool to the Internet for most people in the world in 2020.

- The transparency of people and organisations will increase, but that will not necessarily yield more personal integrity, social tolerance, or forgiveness.

- Voice recognition and touch user-interfaces with the Internet will be more prevalent and accepted by 2020.

- Those working to enforce intellectual property law and copyright protection will remain in a continuing race, with the crackers who will find ways to copy and share content without payment.

- The divisions between personal time and work time and between physical and virtual reality will be further erased for everyone who is connected, and the results will be mixed in their impact on basic social relations.

- Next-generation engineering of the network to improve the current Internet architecture is more likely than an effort to rebuild the architecture from scratch.

- The experts disagree about whether this will lead to more social tolerance, more forgiving human relations, or better home lives.

Read more about the future of the Internet in the pdf at http://www.pewinternet.org/PPF/r/270/report display.asp.

\section{Great 3D wall search engine}

Cooliris is a new search engine which allows users to preview thousands of images and video and more hosted by multiple Web sites via an interactive slideshow, or '3D wall', without leaving the original search page. The result: a 'lightning fast' way of browsing the Web that makes navigating from page to page a thing of the past. The p lug-in lets you browse with speed and ease and works with many different browsers and platforms. Cooliris, Inc., founded in January 2006, aims at creating products that make discovering and enjoying the Web more exciting, efficient and personal. The company's core products include Cooliris (formerly PicLens), which transforms your browser into an interactive, fullscreen 'cinematic' experience for Web media, and CoolPreviews, which lets you preview links instantly. When you click on an image in the 3D wall, you have the possibility to jump to the original page (e.g. news item) that showed it. Besides images you can also see movie trailers. The engine comes with a host of features including search, tracking favourites, shopping, mail as well as availability for the Web and iPhone. Check it out and download it from http://www.cooliris.com.

\section{Phor photo phreaks}

If you are a photographer or simply like to view beautiful or interesting pictures, then take a look at a couple of interesting sites that display images in a new and different way. Earth Album is a mash-up of Flickr and Google Maps and gives you in the first instance a map of the world. Click on any country and photos relating to it appear in a strip on the top of the screen. If you click on an image you can see it larger and also get a description provided by the photographer. You can zoom in on the map to individual states, cities and areas, including streets. As you might expect, some places or tourist areas have more photos associated with them than less known spots. Be aware that since the top Flickr images (and their tags) are used, the images change every few weeks. But it's an interesting way to see the world from the comfort of your own chair! Take a look at http://www.earthalbum.com. 
Another site that takes Flickr photos and creates a stunning visual representation is Tag Galaxy When you enter a tag or keyword you get a 3D representation of a solar system with the keyword as the sun, orbited by any related word 'planets'. By clicking on a planet you can combine keywords or tags and get a new sun. If you then click on the sun you will get a unique photo-sphere that covers itself with images relating to your chosen tags pulled from Flickr. You are able to spin the globe in any direction with the mouse and click on images for close-ups and details. There is also the possibility to jump to the Flickr page showing the image. Apply your own Boolean search logic at http://www.taggalaxy.de.

\section{Love Food Hate Waste}

Nearly seven million tonnes of food is thrown away from UK homes each year - a third of the food bought - with a cost to consumers of a staggering $£ 10$ billion a year. As a result, a campaign has been set up to provide practical help to cut back on all this waste. The Love Food Hate Waste campaign aims to raise awareness of the need to reduce food waste. The campaign shows that by doing some easy practical everyday things in the home we can all waste less food, which will ultimately benefit our purses and the environment too. 'Love Food, Hate Waste' is an initiative of WRAP, which is also responsible for encouraging recycling and home composting. WRAP is funded by the UK government and works to encourage and enable businesses and consumers to be more efficient in their use of materials and recycle more things more often. This helps to minimise landfill, reduce carbon emissions and improve the environment. The Love Food Hate Waste Web site covers aspects such as p ortion size, recipes, tips for storage and preservation, food waste, saving time and money, food facts and why not wasting food matters. The campaign seems to be successful as research has shown that since its start in 2007, almost two million more households in the UK have saved $£ 300$ million worth of food going to waste by cutting back on throwing food away. See how to re-use your leftovers at http://www.lovefoodhatewaste.com.

\section{Explore Mars via Google Earth}

NASA and Google have recently announced the release of a new Mars mode in Google Earth that brings to everyone's desktop a high-resolution, three-dimensional view of the Red Planet. Besides providing a rich, immersive 3D view of Mars that will aid public understanding of Mars science, the new mode, Google Mars 3D, also gives researchers a platform for sharing data similar to what Google Earth provides for Earth scientists. The mode enables users to fly virtually through enormous canyons and scale huge mountains on Mars that are much larger than any found on Earth. Users also can explore the Red Planet through the eyes of the Mars rovers and other Mars missions, providing a unique perspective of the entire planet. Users can see some of the latest satellite imagery from NASA's Mars Reconnaissance Orbiter and other probes orbiting the Red Planet. In addition, viewers can learn about new discoveries and explore indexes of available Mars imagery. The new Mars mode also allows users to add their own 3D content to the Mars map to share with the world. You can d ownload Google Earth at Earth.google.com. The Beta 5.0 version also allows users to explore the 3D ocean floor, visiting mountains, valleys and vistas all under sometimes kilometres of water. Read more about this possibility at http://www.gearthblog.com/blog/archives/2009/02/post_3.html.

\section{About the author}

Dr David Raitt is senior technology transfer officer with the European Space Agency in the Netherlands. His work involves finding applications for space technologies in non-space sectors, particularly those useful for improving everyday life. An information scientist by education and training, David is also editor of The Electronic Library and chairman of the 
Internet Librarian International conferences.

ISSN 1560-683X

Published by InterWord Communications for Department of Information and Knowledge Management, University of Johannesburg 